\title{
Karin Lindvall - an appreciation
}

\section{Kate Khair}

It is with great sadness that we report the death on 12 October 2014 of Dr Karin Lindvall, a founding member of our editorial board, after a short illness.

Karin was the Haemophilia nurse coordinator at the Center for Thrombosis and Hemostasis in Malmö, Sweden, where she provided comprehensive care for both children and adults with hemophilia and related bleeding disorders.

Karin was dedicated to her work at the Malmö centre and especially to the patients, many of whom she followed from birth to adulthood. The Malmö centre supported the backbone of Karin's work, and she was an enthusiastic contributor to all aspects of its work, not least its research programme. Karin was a key member of the team, and over time developed her own research, about the impact of living with haemophilia from the patient/family perspective. She was passionate about this work, which has contributed much to our current understanding of health-related quality of life and adherence in haemophilia. Her key papers included:

- Knowledge of disease and adherence in adult patients with haemophilia (2010)

- The Swedish version of the Haemophilia Activity List (2011)

- Quality of life in adult patients with haemophilia - a single centre experience from Sweden (2012)

- Daily dosing prophylaxis for haemophilia: a randomized crossover pilot study evaluating feasibility and efficacy (2012)

- Health related quality of life in patients with haemophilia and their caregivers (2013)

- Increased burden on caregivers of having a child with haemophilia complicated by inhibitors (2014)

Her contribution to haemophilia was recognised by peers and patients with the award in 2010 of the Arosenius Scholarship. The Arosenius Fund supports research and development in aid of persons with haemophilia, named after the artist Ivar Arosenius who suffered from haemophilia.

In May 2013, Karin became the first haemophilia nurse to

Dr Kate Khair, Consultant Nurse, Great Ormond Street Hospital for Children NHS Foundation Trust, London WC1N 3JH; Visiting Professor of Health and Social Care, London South Bank University; Email: kate.khair@gosh.nhs.uk be awarded a PhD (Doctor of Philosophy) for her work on health-related quality of life and adherence in haemophilia. For most students, a full-time PhD usually takes about three years to complete, and involves formal study in addition to a research project. Within 12 months of completion of the work, a thesis of around 100,000 words must be submitted and defended at an interview (viva voca) by at least two examiners who may ask for revisions to the thesis before the degree is granted. It is to her credit that Karin chose to undertake her PhD through the tougher publications route while continuing to work full time with her patients. This approach can take several years to complete as it is dependent on securing research grants, getting studies approved and achieving good publications before defending the work as a whole. Each of those stages represents a particularly challenging hurdle for nurses to overcome.

Karin was also ambitious for her fellow nurses. She worked extensively with colleagues in the pharmaceutical industry, seeing this as a way to strengthen and improve haemophilia care beyond Sweden. Karin was a member of several advisory boards, groups and industry-sponsored projects. She worked with Bayer HealthCare, for instance, in developing a scholarship programme through which she was active in training nurses in those countries where haemophilia care was less developed. For several years she played an active role on the steering committee behind the company's annual nurse conference. She was always willing to step in and present when others were unable to do so. Colleagues who worked with Karin in those meetings recall that while she gave the impression of being a shy and thoughtful person, she was always able to make her point based on the knowledge and the experience that she had accumulated, beneath that quiet exterior was a lady with a wicked sense of humour!

Karin was also a member of the World Federation of Hemophilia, supporting development of the allied health care team in emerging countries. She made an enormous contribution to haemophila nursing and will be missed by all who knew and worked with her. One of Karin's last pieces of work was investigating the outcomes of portacaths in children with haemophilia in the PedNet study. This work will continue. Karin was also keen to undertake further research into the impact of growing up as the sibling of a boy with haemophilia. Continuation of this research would provide a fitting tribute.

Karin is survived by her husband Richard and her son Johan, who is studying medicine. Johan is as kind and caring as his mother, and so Karin's influence in health care will continue. 